\title{
Retratos e memórias: valorização da história e patrimônio cultural de Formosa do Sul/SC
}

\author{
André Luiz Onghero* \\ Daiane Frigo ${ }^{* *}$ \\ Mirian Carbonera ${ }^{* * *}$
}

Portraits and memories: valorization of the history and cultural heritage of Formosa do Sul/SC

\section{Palavras-chave: \\ Memória \\ Patrimônio Cultural \\ Política Cultural}

Keywords:

Memory

Cultural heritage

Cultural Policy
Resumo: Este artigo procura analisar a experiência de valorização da história e do patrimônio cultural desenvolvida em Formosa do Sul, Oeste de Santa Catarina, a partir do projeto de pesquisa e extensão "Patrimônio-Escola-Comunidade Formosa do Sul", realizado pelo Centro de Memória do Oeste de Santa Catarina (CEOM/ Unochapecó) entre os anos de 2010 e 2012. Mais do que apresentar os objetivos e resultados do projeto, este artigo busca evidenciar os desdobramentos, no âmbito cultural, ocorridos no município, incluindo a criação de um museu municipal, desenvolvimento de projetos culturais e a implantação do Sistema Municipal de Cultura.

\begin{abstract}
This article aims to analyze the experience of valuing the history and cultural heritage developed in Formosa do Sul, west of Santa Catarina, based on the research and extension project "Patrimônio-Escola-Comunidade Formosa do Sul" performed by Centro de Memória do Oeste de Santa Catarina (CEOM/Unochapecó) between 2010 and 2012. More than presenting the objectives and results of this project, this article seeks to highlight the developments, in the cultural scope, occurred in the town, including the creation of a municipal museum, development of cultural projects and the implementation of the Municipal Culture System.
\end{abstract}

Recebido em 13 de agosto de 2019. Aprovado em 10 de setembro de 2019.

\section{Apresentação}

Formosa do Sul é um município situado no Oeste do Estado de Santa Catarina, na região do Sul do Brasil. Emancipado em 1992, conta com uma população estimada em 2.525 habitantes, em um território de $100.105 \mathrm{Km}^{2}$ (IBGE, 2018) utilizado em cerca de 95\% como área rural. A colonização do município é marcada pela vinda de imigrantes procedentes do Rio Grande do Sul, os quais eram, em sua maioria, descendentes de italianos. As famílias de colonizadores começaram a se instalar no território que compõe Formosa do Sul na década de 1950, dedicando-se principalmente à agricultura. O município ainda mantém forte vínculo com o meio rural; mas, nas últimas décadas, ocorre uma concentração da população na área urbana, que representa cerca de $41,7 \%$, o que contrasta fortemente com os dados da década de 1990, com um percentual de $20 \%$, e de 9,66 na década de 1980 , conforme menciona a Associação dos Municípios do Oeste de Santa Catarina (AMOSC, [s. d.]).

O presente trabalho objetiva analisar as ações realizadas pelo município para valorizar a história local e o patrimônio cultural material e imaterial. Como ponto de partida, apresentamos e discutimos

\footnotetext{
* Mestre em Educação pela Universidade Estadual de Campinas (Unicamp). Historiador do Centro de Memória do Oeste de Santa Catarina (CEOM/ Unochapecó).E-mail: andreo@unochapeco.edu.br.

** Mestre em História pela Universidade Federal da Fronteira Sul (UFFS). Colaboradora do Museu Formosa do Sul. Gestora do Ponto de Cultura Tom sobre Tom: música, expressão e arte.E-mail: daiafrigoo@gmail.com.

*** Doutora em Arqueologia pelo Museu de Arqueologia e Etnologia da USP. Coordenadora do Centro de Memória do Oeste de Santa Catarina (CEOM/Unochapecó). Professora do Programa de Pós Graduação em Ciências Ambientais da Universidade Comunitária da Região de Chapecó (Unochapecó).E-mail: mirianc@unochapeco.edu.br.
} 
a iniciativa da gestão municipal em desenvolver projeto de pesquisa e extensão, que teve como principal produto um livro sobre a história e a memória local. Em seguida, analisamos os desdobramentos decorrentes desse projeto, que resultaram na implantação de um museu municipal, de projetos culturais e do Sistema Municipal de Cultura.

O fio condutor das ações de valorização da memória sociocultural foi desenvolvido a partir do conceito de Burke (1992). Segundo ele, toda atividade humana tem história, tudo tem passado; então, a história e as experiências das pessoas comuns são também processos de mudança social. Os patrimônios e as histórias locais surgem nesse contexto de transformações rápidas, como formas de afirmação da identidade. De acordo com o Manual de Referência do Patrimônio Mundial (UNESCO, 2016), o patrimônio tem ganhado muita importância, já que a modernização e as mudanças sociais são cada vez mais velozes e o passado pode oferecer uma sensação de segurança e pertencimento às sociedades modernas. A noção de patrimônio também foi ampliada, não somente os monumentos são importantes, mas também as paisagens, já que praticamente não há ambiente que não tenha sido tocado pelas ações humanas. Essa nova realidade apresenta desafios aos gestores públicos, já que a implementação das políticas devem ser planejadas em conjunto com os interessados, no caso as comunidades locais. O exemplo do município de Formosa do Sul contribui para pensar não somente nas ações de preservação e valorização da história e do patrimônio local, mas também em trabalhos colaborativos, envolvendo as comunidades, a gestão pública e as instituições universitárias.

\section{Contexto histórico da região Oeste de Santa Catarina}

Como parte da região Oeste de Santa Catarina, o município de Formosa do Sul integra o processo de colonização ${ }^{1}$ ocorrido a partir da década de 1920, quando começam a atuar as empresas colonizadoras ${ }^{2}$, que comercializam lotes de terras, especialmente para famílias agricultoras descendentes de europeus, em sua maioria, italianos, alemães e poloneses (Figura 1).

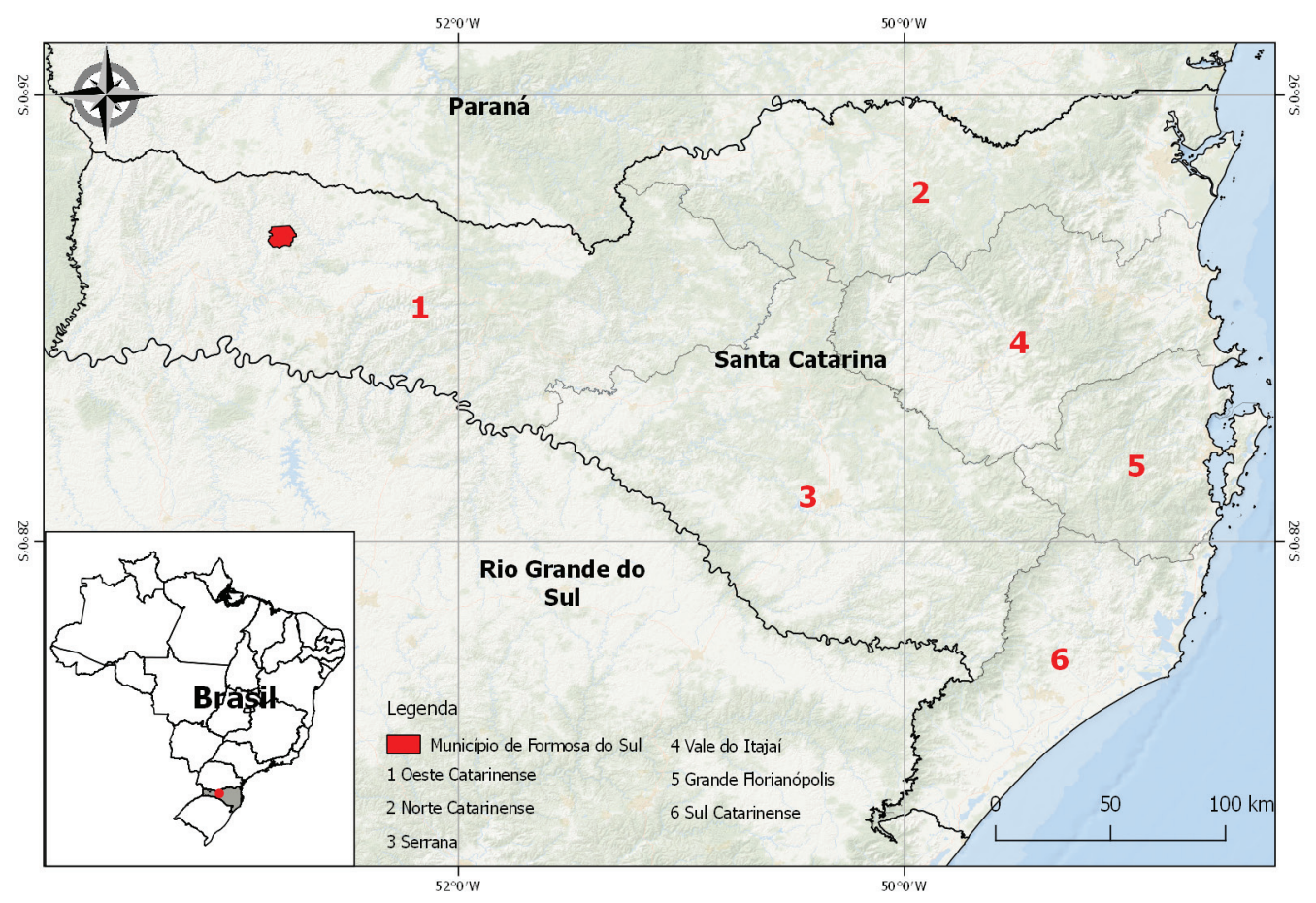

Figura 1: Localização do município de Formosa do Sul no Estado de Santa Catarina Fonte: Elaborada por Vanessa Barrios Quintana (2019). 
Na segunda década do século XX, o território do oeste catarinense era visto como um "vazio demográfico" e a instalação de famílias agricultoras foi uma estratégia para a ocupação efetiva desses territórios (RENK, 1997). A colonização ocorreu por meio da comercialização dos lotes, o que ocasionou uma nova relação com a terra: propriedade privada e regularizada por meio de escritura. Este foi um elemento de conflito entre a nova população que chegava para se instalar e os moradores já existentes - indígenas $^{3}$ e caboclos $^{4}$ - que, em geral, não possuíam registro de propriedade do local onde habitavam. Os povos nativos eram um sinônimo do atraso, enquanto os colonizadores representavam o progresso e a civilização (RENK, 1997, 2004; RADIN; VICENZI, 2017). Nas palavras de Renk (2004, p. 19), "caboclos e índios foram reduzidos ao silêncio". Já os migrantes foram considerados "protagonistas do processo de colonização, tiveram sua imagem positivada" (RADIN; VICENZI, 2017, p. 70).

Os colonizadores vinham principalmente do Rio Grande do Sul, local onde, desde o século XIX, foram criadas colônias de imigrantes europeus como estratégia de povoamento do território da região Sul, em conformidade com a política de "branqueamento" do Brasil adotada durante o império (SEYFERTH, 2002). Como um desdobramento deste processo, ocorreu a expansão da fronteira agrícola para novas áreas, incluindo o Oeste de Santa Catarina ${ }^{5}$.

\section{Projetos e ações de valorização do patrimônio e da história local de Formosa do Sul}

\section{As ações do projeto "Patrimônio-Escola- Comunidade"}

As ações de valorização do patrimônio histórico-cultural do município de Formosa do Sul tiveram início quando a Prefeitura Municipal buscou apoio junto ao Centro de Memória do Oeste de Santa Catarina (CEOM), mantido pela Universidade Comunitária da Região de Chapecó (Unochapecó) para a produção de um livro sobre a história do município. As atividades foram desenvolvidas por meio de um termo de convênio estabelecido entre a Prefeitura e a Universidade, que deu origem ao projeto de pesquisa e extensão denominado "Patrimônio-Escola-Comunidade Formosa do Sul", iniciado em 2010. O projeto tinha como objetivo o registro de aspectos do patrimônio material e imaterial relacionados aos moradores de Formosa do Sul, buscando preservar suas memórias e narrativas acerca da história, a partir de temas como política, trabalho, cultura, etnia, lazer, sociabilidade e educação.

$\mathrm{O}$ projeto foi desenvolvido pelo Centro de Memória do Oeste de Santa Catarina (CEOM/ Unochapecó $)^{6}$, por meio do programa PatrimônioEscola-Comunidade $(\mathrm{PEC})^{7}$, que planejou e executou as etapas do trabalho em conjunto com a Secretaria Municipal de Educação, Cultura, Esporte e Turismo, e contou com a colaboração de uma equipe de moradores de Formosa do Sul. Cabe ressaltar que o programa PEC foi criado no final dos anos 1990, com o objetivo de valorizar as histórias locais, a memória social, a produção do patrimônio coletivo enquanto dimensão cidadã, em uma perspectiva de articular a universidade com a comunidade (DMITRUK, 2000).

A realização do projeto ocorreu em três etapas. A primeira foi dedicada à pesquisa de documentos, fotografias e ao registro de depoimentos orais por meio de entrevistas gravadas em áudio e vídeo. Esta etapa resultou na produção de 16 entrevistas com famílias que protagonizaram a colonização local, incluindo caboclos, descendentes de italianos e descendentes de poloneses. Também foram mapeados objetos com potencial museológico, tendo em vista a viabilidade de criação de um museu municipal. Como resultado deste mapeamento, foram catalogados 31 objetos, a maior parte, relacionados ao universo do trabalho, utilizados no meio rural, e utensílios domésticos anteriores à instalação de energia elétrica.

$\mathrm{Na}$ ocasião das visitas às famílias para a realização de entrevistas, foi possível ter acesso às fotografias de acervos familiares. Entre estas, foram selecionadas imagens que retratavam momentos que não se restringiam ao convívio familiar e traziam 
elementos relacionados à história do município. As fotografias foram digitalizadas e formaram um banco de 134 imagens. Também foram mapeados e digitalizados documentos históricos. Todo o material histórico reunido passou a compor acervo do município, entregue à Prefeitura junto com um relatório das atividades, sendo 16 DVDs com entrevistas gravadas em áudio e vídeo; arquivos digitais das fotografias e documentos históricos; fichas do levantamento de objetos com potencial museológico; e fotografias das pessoas entrevistadas e da Capela São Cristóvão, considerada um importante patrimônio do município. Os moradores que participaram dando entrevista também receberam cópias digitais de seus depoimentos.

A segunda etapa do projeto foi dedicada à produção do livro. Para tanto, foi realizada a transcrição integral das entrevistas, análise das fontes e produção textual. Também foram realizadas reuniões com uma comissão formada por moradores, funcionários da prefeitura, prefeito e equipe do CEOM, com o objetivo de definir conjuntamente a estrutura do livro e as imagens para publicação, além de complementar algumas informações obtidas durante a pesquisa. $\mathrm{O}$ grupo também foi reunido para a leitura do texto e indicação de sugestões e correções. Adotou-se uma abordagem mais inclusiva, com o envolvimento comunitário e não de cima para baixo, fazendo com que os munícipes fossem parte do processo.

A terceira etapa consistiu na edição e publicação da obra "Retratos e Memórias da História de Formosa do Sul" (Figura 2). A publicação foi estruturada em quatro capítulos, agrupando os seguintes temas: 1) paisagem natural como espaço utilizado pelos indígenas, caboclos e colonizadores descendentes de europeus em diferentes épocas para o desenvolvimento de seu modo de vida, enfocando três momentos distintos de povoamento e sua relação com o ambiente natural, especialmente a partir da década de 1950. Nesse capítulo, procurouse também mostrar alguns dos elementos que atraíram as diferentes populações para a região e também que condicionaram suas experiências. 2) A trajetória administrativa do município e as mudanças ocorridas em relação aos serviços de saúde, educação, segurança pública e atendimento religioso. 3) O trabalho e o cotidiano, descrevendo as principais atividades econômicas desenvolvidas no município e analisando o espaço do lar enquanto local de trabalho e sociabilidade, vinculado às tradições e a aspectos culturais próprios das etnias presentes no município. 4) As atividades de lazer e religiosidade como formas de sociabilidade, promovendo o encontro e relacionamento entre as pessoas.

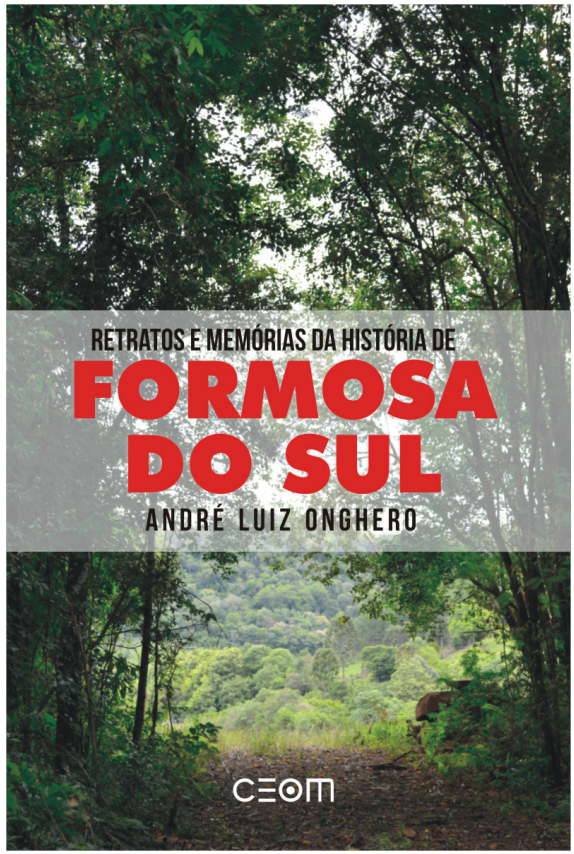

Figura 2: Capa do livro do município de Formosa do Sul Fonte: ONGHERO (2012)

Em toda a obra, procurou-se compreender a colonização do local e formação do município de Formosa do Sul como um processo em que os indivíduos não se encontram isolados, mas agindo em grupo e trocando conhecimentos. Não houve a pretensão de apresentar "os primeiros" ou "os pioneiros", por entender que as atividades desenvolvidas no território que veio a se configurar como município não surgiram ali, mas resultaram das experiências trazidas por migrantes de outras localidades em diálogo com aqueles que já residiam no local.

O lançamento do livro ocorreu em 2013 junto à comemoração do aniversário de 20 anos de instalação do município, em um evento com a presença de autoridades locais e regionais, a 
participação da população de Formosa do Sul e cobertura da imprensa regional. Com 800 exemplares impressos, a gestão municipal comprometeu-se a distribuir um livro para cada família residente no município. Uma versão digital ${ }^{8}$ foi disponibilizada no site da prefeitura, permitindo o acesso gratuito e irrestrito à obra, também com a intenção de facilitar o acesso para pessoas que tinham algum vínculo com o município, mas não residiam nele.

A receptividade da população pode ser considerada positiva, principalmente entre as pessoas idosas, pois muitos fatos importantes da história de formação da comunidade estiveram expressos no livro, relembrando as situações enfrentadas pelos moradores mais antigos. Por outro lado, observaram-se críticas de leitores que tinham o anseio de ver representadas no livro as tradicionais listas com nomes relacionados ao primeiro ferreiro, primeiro carpinteiro, primeiro professor etc.

Essa necessidade de reconhecimento $\mathrm{e}$ representação é um reflexo das características da historiografia até a primeira metade do século XX, a qual conforme, Castro (1997), ocorre por meio de abordagens centradas nos grandes acontecimentos ou nos que são reconhecidos como personagens importantes. Contudo, a proposta de pesquisa para o livro sobre a história de Formosa do Sul esteve baseada na abordagem de diversos aspectos da história social da comunidade, observando as relações e o desenvolvimento do conjunto de sujeitos, do território e suas trajetórias coletivas até o momento de emancipação político administrativa.

Já em 2014, um ano após o lançamento, a primeira tiragem do livro estava esgotada. A gestão municipal decidiu imprimir 500 exemplares em uma nova edição; para tanto, o CEOM/Unochapecó foi contatado novamente para a sua produção. A distribuição da segunda edição esteve focada em contemplar as novas famílias que chegavam ao município, trabalho este realizado a partir do mapeamento das agentes de saúde nos bairros e comunidades rurais. A distribuição do livro também foi realizada a visitantes e pesquisadores que buscavam o setor de cultura e o Museu Formosa do Sul para ter referências sobre o histórico da cidade para o desenvolvimento dos projetos culturais citados a seguir.

\section{Museu Formosa do Sul}

Um segundo desdobramento cultural foi a implementação do Museu Municipal, também iniciado em 2014. Os dados levantados durante o projeto desenvolvido para a produção do livro, das referências patrimoniais - tanto materiais quanto imateriais -, relativas a pessoas, lugares e objetos, contribuiu para estabelecer as linhas de pesquisa, os indicadores, os programas de acervos $\mathrm{e}$ as exposições do Museu.

Com base nessas informações, o Museu definiu, entre suas linhas de pesquisa, o estudo do “[...] desenvolvimento do território de Formosa do Sul e seu entorno, etnias, memória, cultura e lazer, trabalho e cotidiano, saberes tradicionais, patrimônio material, imaterial e natural" (BEN; ARGENTA; RAFAEL, 2016, p. 15). No que se refere aos acervos e às referências de moradores antigos da comunidade, o mapeamento dos objetos realizado pela equipe do CEOM foi incorporado pelo Museu, passando a compor seu banco de dados, contribuindo para estratégias de ampliação das pesquisas e busca por novos referenciais.

Em seu Programa de Exposições, o Museu prevê, além das exposições de longa e curta duração, os percursos de visitação, que contemplam a visita a famílias do meio rural e urbano que conservam acervos com potencial museológico - principalmente ferramentas e objetos de uso agrícola, especialmente até a década de 1980 - trabalho este que surgiu também como reflexo dos dados apresentados na pesquisa para a produção do livro.

O Museu Municipal foi criado pela Lei ${ }^{\circ}$ 597/2013, inicialmente como Museu Histórico e posteriormente tendo seu nome alterado pela Lei no 621/2014 para Museu Formosa do Sul. A implantação de um Museu no município teve o objetivo de reunir, abrigar e preservar o patrimônio cultural, artístico e histórico da região e foi possibilitada pelo Edital Mais Museus (2011/2012) promovido pelo Instituto Brasileiro de Museus (IBRAM), autarquia do Ministério da Cultura 
que estimulou pequenos municípios, de até 50 mil habitantes a criarem o seu primeiro museu. $\mathrm{O}$ imóvel, sede do Museu, é a antiga Casa da Cultura localizada no centro do município, uma das poucas edificações históricas conservadas, que data de 1960. O espaço foi reformado, com adequação das salas expositivas e melhorias na parte externa, efetivadas com recursos dos governos municipal e estadual (Figura 3).

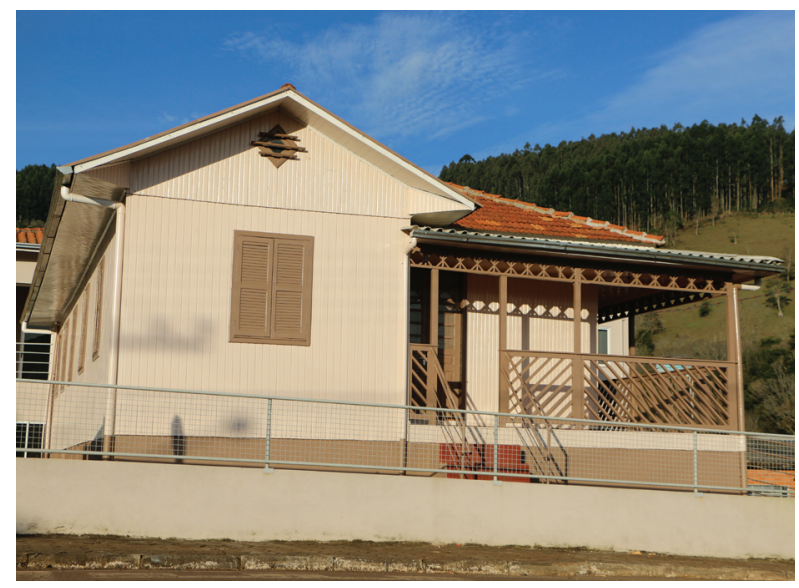

Figura 3: Museu de Formosa do Sul

Fonte: Acervo Digital Museu Formosa do Sul (2019).

Para a realização do projeto, foi contratada uma empresa de consultoria especializada e formada uma comissão de acompanhamento local, com servidores da prefeitura e membros da comunidade. A metodologia do trabalho envolveu a definição institucional (incluindo valores, missão e objetivos), seguida da discussão e criação de uma política de acervos (aquisição e descarte), seleção e catalogação/inventário do acervo já existente, produção de material didático e documentário para ações educativas, além da elaboração das exposições.

A missão do Museu, conforme estabelece seu Plano Museológico, é promover a interação da sociedade com o patrimônio cultural de Formosa do Sul, com ênfase na sua história e memória, através da preservação, pesquisa e comunicação dos bens culturais sob a guarda da instituição de forma democrática e participativa (FORMOSA DO SUL, 2015). O processo de implementação foi concluído em agosto de 2016, com a inauguração do Museu ${ }^{10}$.

\section{Projetos Culturais}

Durante o processo de produção do livro e implantação do Museu, foram também desenvolvidos projetos culturais que contribuíram para sensibilizar a comunidade local e valorizar saberes, fazeres e formas de expressão da cultura popular regional.

Entre as iniciativas desse período, podemos citar os projetos "Ponto de Cultura" e "Cine Mais Cultura", desenvolvidos a partir de 2010 em parceria com a Associação de Artesãos Artefor, com o objetivo de incentivar o desenvolvimento de oficinas de formação, expressão e fruição de saberes por meio de artesanato, dança, teatro, música e cinema. Também se destacou o projeto "Alegria de viver: história, cultura e arte", desenvolvido no ano de 2011 por meio do Prêmio Inclusão Cultural da Pessoa Idosa, em parceria com a Associação do Grupo de Idosos, cuja finalidade foi registrar e representar a história, a cultura e os costumes relacionados à cultura popular da região.

Em parceria com o Museu Histórico de Pinhalzinho ${ }^{11}$, foram realizados os projetos "Degustando saberes: salvaguarda das formas e expressões dos alimentos e da culinária tradicional do oeste catarinense" e "Tempo di recordare: saberes, fazeres e expressões da cultura ítalobrasileira no oeste catarinense", com o mapeamento do patrimônio cultural imaterial dos municípios da região $0^{12}$.

As festas populares em honra aos santos padroeiros representam formas de sociabilidade e união comunitária, tendo grande representatividade nas comunidades locais. Como forma de preservar uma das festas mais antigas do município, foi desenvolvido, em 2016, em parceria com a comunidade, o projeto "Registrando memórias: a tradicional festa de São Cristóvão em Formosa do Sul”.

As festas religiosas podem ser consideradas momentos em que há o fortalecimento das tradições populares, marcadas por grande envolvimento social, desde os preparativos até o dia de sua realização. Preservar as tradições, por meio de comemorações como estas, representa não só uma atividade de cunho social, mas também demonstra 
como os grupos sociais respeitam a ancestralidade e suas crenças, mantendo vivas suas manifestações e criando novas formas de interação no contexto contemporâneo.

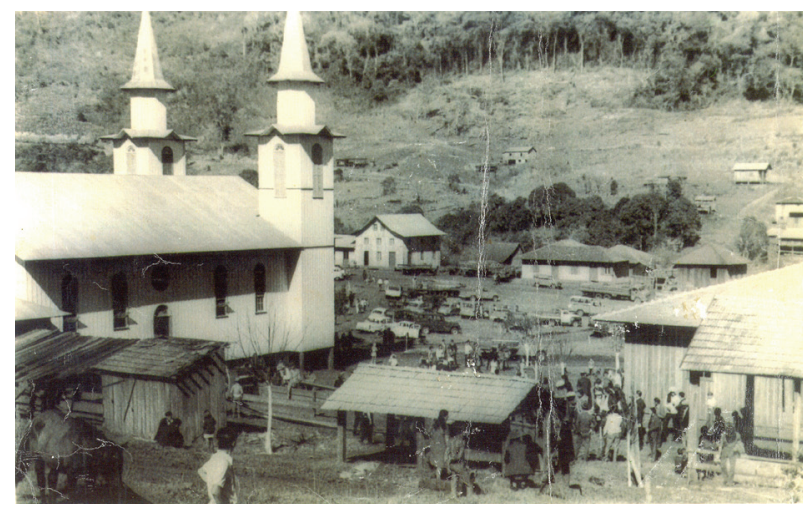

Figura 4 - Festa de São Cristóvão na década de 1960 Fonte: Museu Formosa do Sul (2019).

\section{Sistema Municipal de Cultura}

No campo das políticas públicas de cultura, estimulado pelo Ministério da Cultura, o município implementou, a partir de 2012, o seu Sistema Municipal de Cultura, com base em uma concepção de cultura em três dimensões: simbólica, cidadã e econômica. Assim, a importância estratégica da criação do Sistema Nacional de Cultura, pelo Ministério da Cultura, e o estímulo aos Estados e Municípios para criarem os seus próprios sistemas é enfrentar os desafios de "[...] assegurar a continuidade das políticas públicas de cultura como políticas de Estado, com um nível cada vez mais elevado de participação e controle social" (PEIXE, 2011, p. 14), viabilizando estrutura e recursos em todas as esferas governamentais.

A partir da elaboração do Sistema Municipal de Cultura, o município criou o Conselho Municipal de Política Cultural, o Fundo Municipal de Cultura e desenvolveu, de forma colaborativa, o Plano Municipal de Cultura, este aprovado em maio de 2016. Como ferramenta de gestão, o Plano “[...] representa o desejo e o compromisso da administração pública municipal de desenvolver o campo da cultura em consonância com os anseios da comunidade" (FORMOSA DO SUL, 2016, p. 4), valorizando e potencializando a diversidade cultural.
O Plano apresenta, além do diagnóstico do setor cultural, metas que contemplam diversos segmentos, entre eles, o patrimônio cultural, com ações que preveem a valorização e salvaguarda das expressões de mestres, grupos e detentores de saberes da cultura popular tradicional, além de promoção de medidas cautelares de proteção e preservação do patrimônio histórico, cultural e ambiental. Como um instrumento de gestão, o Plano Municipal de Cultura age como elemento propulsor na garantia de acesso aos bens $\mathrm{e}$ serviços culturais, direitos fundamentais para uma sociedade democrática, que considera a diversidade cultural e confere atenção ao patrimônio cultural, de forma que a sua implementação "[...] deve partir do anseio das comunidades e ser norteada pela delimitação democrática dos bens reconhecidos como merecedores de preservação" (FUNARI; PELEGRINI, 2009, p. 59).

\section{Narrativas do passado como afirmação identitária}

O patrimônio cultural compreende um conjunto de manifestações, bens, tradições e representações de natureza material e imaterial. Sua construção social pode ser entendida como produto dos significados e valores atribuídos por determinado grupo ao que entende como seu legado. A palavra de origem latina (patrimonium) se refere a tudo que pertence ao pai, pois o "patrimônio era patriarcal, individual e privativo do aristocrata" (FUNARI; PELEGRINI, 2009, p. 11). A caracterização de um patrimônio ou a permanência dele enquanto elemento vivo no interior de uma comunidade depende exclusivamente da sociedade. Já os processos de patrimonialização tornam-se dependentes do poder público e da sociedade, pois são esses dois agentes que optam sobre o que conferir valor e os meios de salvaguardar ou dar continuidade às manifestações.

O surgimento de discursos justificando a necessidade de preservação da memória, de forma a garantir a existência da história, carregam narrativas que se constroem a partir das percepções dessa memória no presente. Para Meneses (1992) 
e Chartier (2007), história e memória possuem aproximações, mas são conduzidas por exigências diferentes. Enquanto a história se baseia em saberes universais, a memória tem no passado a legitimação de saberes, tradições, narrativas e hierarquizações do presente (SARTORI, 2018).

$\mathrm{Na}$ narrativa dos sujeitos que pretendem elucidar sua história ou a trajetória do grupo que se entendem como parte, as memórias, sejam estas individuais ou coletivas, no que se refere à reconstrução do passado, carregam muitas vezes interesses particulares na tentativa de consolidar a ideia de pertencimento e continuidade do conjunto social. Assim, quem narra, ao mesmo tempo em que se reconhece, legitima o reconhecimento do grupo social do qual faz parte, permitindo uma representação que se entende como autêntica e fundamental para a história (MICHELON; MACHADO JR.; GONZÁLEZ, 2012)

Para Candau (2012, p. 159), a busca memorial e a patrimonialização, pela via da afirmação identitária, deixam perceber que "[...] certa incapacidade em viver no tempo presente, responde a uma demanda social em direção ao passado". Essa demanda, em que se buscam traços identitários na revisão do passado, em vestígios, arquivos, relíquias e narrativas, tem o papel de reforçar ou legitimar a importância dos fatos, e a importância dos sujeitos "fazedores de história". O legado que se pretende deixar, "num esforço de enraizamento na terra natal", não representa, assim, mais do que "ilusões de eternidade" (CANDAU, 2012, p. 159), em que alguns princípios e valores são destacados, bem como narrativas tidas como significativas.

Nesse jogo de preservar, o que lembrar ou o que esquecer, alguns aspectos são privilegiados enquanto outros são esquecidos, de forma que os valores escolhidos pelo grupo a serem preservados representam aquela comunidade e seu passado, afirmando sua identidade. O fruto dessas escolhas interfere diretamente no acesso das gerações futuras a essas informações, uma vez que serão mediadas pelo direcionamento que os atores sociais daquele processo determinaram. Esse processo revela consequentemente o conteúdo dos discursos, de forma que "[...] a história como discurso de caráter oficializante e unificador promove elementos que servirão de uso do passado reivindicado na valoração e significação patrimonial presente" (MICHELON; MACHADO JR; GONZÁLEZ, 2012, p. 7-8) Por isso, questionar esse processo de produção de narrativas e afirmação identitária aponta uma linha tênue entre a salvaguarda como ressignificação do próprio presente e o reforço de um "discurso oficial" da história.

Assim, discutir os processos de patrimonialização das memórias requer não só o interesse público em revisitar o passado como também considerar que "[...] a proteção do patrimônio cultural consiste em um trabalho de reapropriação, restituição e reabilitação do próprio presente, em prol de um futuro de relações sociais mais justas" (MICHELON; MACHADO JR.; GONZÁLEZ, 2012, p. 7). É nesse processo de reabilitação do presente que as ações desenvolvidas em Formosa do Sul, além de revisitarem o passado, tencionam as relações vividas no agora, uma vez que permitem pensar nas contribuições de diferentes grupos sociais à formação histórica regional e não somente à trajetória de descendentes de europeus, enquanto grupo, de certa forma dominante, no cenário de desenvolvimento socioeconômico.

Tendo em vista essas considerações, as políticas públicas, enquanto conjunto de ações de Estado para atender às demandas da sociedade, sempre buscam atingir certos objetivos. Dentro desse espectro de objetivos que podem ser elencados, a sociedade, por meio de seus representantes, seleciona o que será patrimonializado e ressignificado; “[...] por essa razão, o ato de valorização implica que algo será priorizado em detrimento de outro, motivo pelo qual sempre há possibilidade de um conflito, latente ou explícito" (MICHELON; MACHADO JR.; GONZÁLEZ, 2012, p. 9). O conflito aqui é eminente, visto que não há uniformidade ou consensos em relação às prioridades apontadas por um grupo de pessoas, pois a diversidade de pontos de vista é característica de toda sociedade.

Em relação ao projeto desenvolvido para elaboração do livro no município de Formosa do Sul, um pequeno grupo de 13 pessoas, envolvendo 
gestores públicos e antigos moradores do município e seus descendentes, foi responsável por estabelecer, junto com a equipe do CEOM/Unochapecó, as prioridades da pesquisa. As reuniões do grupo traçaram os possíveis participantes (entrevistados) e analisaram a produção textual, as fotografias, bem como os depoimentos coletados pelos pesquisadores. Nesse sentido, surgiram questionamentos dentro da comunidade sobre por que algumas pessoas foram escolhidas a participar e outras não. Em outros projetos, é possível que tal questionamento também tenha estado presente.

É nesse ponto que "o ato de valorização implica que algo será priorizado" e sempre haverá a possibilidade de conflito, pois inevitavelmente uma pesquisa se baseia em um conjunto limitado de sujeitos e informações, tentando contemplar de forma mais ampla a coletividade. Nesse exercício de reflexão, os pontos de vista não são unívocos, nem são compartilhados por toda coletividade; assim, "[...] o exercício da cidadania pressupõe isso mesmo, a multiplicidade de olhares e a convivência das diferenças, na qual cada sujeito é protagonista de um olhar, que similar ou diverso dos outros, ocupa lugar significativo na construção simbólica e cidadã" (FRIGO, 2018, p. 3).

Contudo, a opinião é sempre individual e se refere a primeira pessoa, de forma que "nada indica que duas pessoas produzam a mesma interpretação do mesmo acontecimento" (CANDAU, 2012, p. 36). Afinal, ainda que existam lembranças compartilhadas, as interpretações individuais diferem e transformam os fatos em frágeis recortes na memória de cada um. Mas, nesse ponto, uma particularidade pode ser apontada em um município de pequeno porte, como Formosa do Sul, considerando a baixa densidade populacional. Podemos constatar que existe o que Candau (2012, p. 44-45) chama de "conhecimento recíproco" entre seus membros, o que propicia a constituição de uma memória coletiva que será caracterizada como uma memória organizada forte, “[...] massiva, coerente, compacta e profunda, que se impõe a uma grande maioria dos membros de um grupo, qualquer que seja seu tamanho [...]", Mesmo não sendo ainda única e reconhecida por todos.
Na constituição dessa memória "massiva", o reconhecimento da atuação por parte de descendentes de europeus no desenvolvimento local é predominante. Assim, com o objetivo de repensar a construção histórica, as memórias, bem como às contribuições de diferentes atores sociais ao desenvolvimento local, a construção narrativa do circuito expositivo no Museu, bem como na elaboração do livro, esteve amparada na experiência de dialogar com sujeitos de diferentes origens étnicas e sociais, ouvindo os moradores do centro urbano e da zona rural, os descendentes de italianos e alemães, assim como as pessoas de origem cabocla, reunindo informações de diferentes fontes, enfatizando aquele que invariavelmente tem sido esquecido, o sujeito caboclo, nem sempre lembrado por suas contribuições à história local e regional. Com esta iniciativa, o Museu e o município contribuem para uma "contra-história desta minoria" (RENK, 1997, p. 11), ato que não dissolve as fronteiras sociais, mas tenciona sua consistência nas relações cotidianas e nos processos de construção da história e produção do conhecimento no presente.

Com estas considerações sobre a experiência vivenciada no municípiode Formosa doSul, procurase refletir sobre os conflitos entre a memória e o esquecimento nas ações de patrimonialização, papel este a ser exercido por Museus, projetos e políticas sociais, propondo repensar as relações e o modo de vida, de forma que a sociedade vislumbre o seu papel de "[...] comunidade criadora, de uma ordem social em que as identidades se interconectam [...] para o enriquecimento humano e a solidariedade" (FRIGO, 2019, p. 121).

\section{Considerações finais}

Considerar o papel dos sujeitos históricos de Formosa do Sul como protagonistas, reconhecendo a história e o patrimônio local e percebendo sua importância para o fortalecimento da identidade, remete a identificações historicamente construídas que dão sentido a um grupo. Implica um sentimento de pertença a um determinado grupo étnico, cultural, religioso, em contraposição às diferenças percebidas nos outros (RODRIGUES, 
2012). A construção de uma narrativa histórica para o município de Formosa do Sul buscou agrupar as trajetórias individuais em torno da coletividade centralizada de um povoado, tentando entender, ao mesmo tempo, a particularidade do local e o caráter mais abrangente das relações sociais, das atividades econômicas e dos aspectos culturais.

A experiência vivenciada no município de Formosa do Sul trouxe, a partir da atuação dos profissionais da área cultural, envolvidos na gestão, das parcerias e ações em rede para o desenvolvimento de projetos culturais, que são construídas pela população local, novas perspectivas em relação à concepção de patrimônio cultural. $\mathrm{O}$ repertório cultural é ampliado, permitindo "novos olhares da comunidade sobre si mesma, no passado, no presente e para o futuro" (FRIGO, 2018, p. 4). Dessa forma, a perspectiva cultural construída pelos gestores e pela coletividade de sujeitos sociais possibilitam a conexão de pessoas, projetos, territórios, expressões e modos de vida, ressignificando formas de interação e sociabilidade, indicando novos horizontes para o exercício da cidadania.

Os projetos e as iniciativas descritos compreendem um conjunto de ações desenvolvidas de forma integrada, nas quais o conceito de patrimônio cultural é construído em amplo aspecto e as iniciativas e ações culturais aconteceram de forma participativa e colaborativa. Nessa relação, patrimônio, cultura, memória e história se fundem nas inúmeras representações que permitem aos envolvidos ressignificar tradições, acessando novas formas de expressão e reconceituando o papel do indivíduo na formação da sociedade.

Esperamos que a experiência relatada neste artigo possa contribuir para a discussão e reflexão acerca do patrimônio cultural e, quem sabe, inspirar outras iniciativas, que valorizem processos colaborativos na produção de conhecimento $\mathrm{e}$ valorização da coletividade, já que ainda há tanto a ser realizado no segmento cultural, o qual é um importante vetor na transformação da sociedade.

\section{Agradecimentos}

Equipe e pesquisadores do CEOM, Servidores da Prefeitura Municipal e participantes das pesquisas e projetos em Formosa do Sul, Equipe do Museu Histórico e do Departamento de Cultura de Pinhalzinho, Associação do Grupo de Idosos Formosense, Associação de Artesãos Artefor de Formosa do Sul, Catavento Gestão e Produção Cultural, colaboradores e parceiros dos municípios vizinhos.

\section{Notas}

1 Sobre esse tema existem diferentes produções bibliográficas. Entre os autores, destacam-se: Renk (1997, 1999, 2004), Eidt (1999, 2009), Jungblut (2000), Werle (2001), Poli (2001, 2002), Simoni (2003), Vicenzi (2008), Werlang (2006), Radin (2009), Radin e Vicenzi (2017).

2 Conforme Radin e Vicenzi (2017) a colonização do Oeste catarinense foi conduzida preponderantemente por empresas colonizadoras privadas que receberam da Diretoria de Terras, Colonização e Agricultura do estado catarinense os títulos de concessão de terras. Em um contexto de limitada capacidade de investimentos do Estado, as empresas colonizadoras também executavam tarefas de infraestrutura, como abertura de estradas e pontes, entre outras obras, que diminuíam sua dívida com o Estado em relação à aquisição das terras.

3 De acordo com pesquisas arqueológicas, o povoamento da região remonta há cerca de $10 \mathrm{mil}$ anos, por grupos caçadores e coletores. Por volta de 2 mil anos atrás, o Sul do Brasil, incluindo o Oeste de Santa Catarina, passou a ser povoado por agricultores ceramistas Guarani e povos relacionados ao tronco linguístico Jê, entre os quais ainda se encontram habitando os Kaingang (CARBONERA; ONGHERO; LINO, 2017). No século XIX, os Kaingang sofreram a expulsão de grande parte de seu território durante o processo de ocupação das áreas de campos por fazendeiros, ficando, assim, em grande parte, restritos aos aldeamentos. Com a atuação das companhias colonizadoras no século XX, alguns grupos indígenas não aldeados tiveram as terras em que viviam vendidas a colonos, sendo retomadas apenas a partir da década de 1980. A respeito deste assunto, ver D’Angelis (2006); Fernandes (2003), Piovezana (2010), Souza (2012) e Nacke et al. (2007).

4 Nas primeiras décadas do século XX, os caboclos que viviam na região eram uma população rarefeita, que se dedicava à agricultura de pequena escala voltada à subsistência e a atividades extrativistas (RENK, 1997). Neste contexto, o caboclo era o morador do sertão e, em contraposição ao colonizador de origem europeia, é chamado de "brasileiro". Com a constituição da territorialidade dos colonizadores, a população cabocla teve o seu modo de vida desestruturado. De modo geral, a compra e a venda das terras não faziam parte de suas práticas; e, sem possuir registro de propriedade, foram considerados intrusos. Foram, então, empurrados 
para as áreas íngremes, não postas ou não concorridas no mercado fundiário, e também se alojaram nas áreas próximas aos rios, aproveitando-as para pesca e praticando agricultura em pequena escala (RENK; CONFORTIN, 2017).

5 A colonização da região teve início somente após a criação do município de Chapecó em 1917 - que abrangia toda a região, com cerca de $14 \mathrm{mil} \mathrm{km}^{2}$ - pois antes houve disputas sobre a posse do território entre Brasil e Argentina (resolvida em 1895) e entre os estados do Paraná e Santa Catarina, cujo acordo de limites foi firmado em 1916 (WERLANG, 2006).

6 O Centro de Memória do Oeste de Santa Catarina (CEOM) iniciou suas atividades em 1986, sendo um dos primeiros programas de pesquisa e extensão da Fundação Universitária do Desenvolvimento do Oeste (Fundeste). Atualmente, o CEOM é vinculado à Universidade Comunitária da Região de Chapecó (Unochapecó) e está vinculado à Diretoria de Extensão. Objetiva salvaguardar acervos arqueológicos, documentais e bibliográficos, sejam eles, materiais e imateriais, realizar e estimular pesquisa, comunicação e extensão universitária em Patrimônio Cultural, Memória, História, Arquivologia, Arqueologia e Museologia, com enfoque na região Oeste de Santa Catarina. O centro estabelece ampla comunicação com a população do oeste catarinense, a qual ocorre por meio de publicações, eventos e das ações educativas. Maiores informações podem ser obtidas no site https://www.unochapeco.edu.br/ceom e, também, em Argenta (2011), Carbonera et al. (2017), Oliveira (2007) e Vitória (2017).

7 Programa do CEOM voltado ao atendimento das demandas de prefeituras municipais e instituições que desejam produzir material sobre sua história, estabelecendo convênios específicos para cada projeto. Inicialmente o programa Patrimônio-EscolaComunidade (PEC) articulava ações de valorização do patrimônio histórico e cultural, como criação de museus e espaços de memória, além de produzir obras de histórias locais elaboradas coletivamente com professores do curso de História da universidade, estagiários e equipes formadas por professores de História do município que firmava o convênio. Posteriormente, as atividades técnicas passaram a ser concentradas na atuação dos profissionais e estagiários do CEOM, mas sempre em diálogo com a comunidade. Maiores informações sobre o programa podem ser obtidas nas publicações de Dmitruk (2000) e Onghero (2011).

8 A versão digital da primeira edição livro "Retratos e Memórias da História de Formosa do Sul” pode ser acessada em: https://static.fecam.net.br/uploads/362/ arquivos/19149_Livro_Retratos_e_Memorias_da_ Historia_de_Formosa_do_Sul__Versao_Digital.pdf.

9 O Plano Museológico é compreendido como ferramenta básica de planejamento estratégico, de sentido global e integrador, indispensável para identificar a vocação da instituição museológica para a definição, o ordenamento e a priorização dos objetivos e das ações de cada uma de suas áreas de funcionamento, bem como fundamenta a criação ou a fusão de museus, constituindo instrumento fundamental para a sistematização do trabalho interno e para a atuação dos museus na sociedade, conforme dispõe o Estatuto de Museus, Lei no 11.904/2009, art. 45 (BRASIL, 2009)

10 Maiores detalhes e informações sobre a implantação do Museu Formosa do Sul podem ser obtidas em: https://docs.wixstatic.com/ugd/2ce448_41823e3 a50b14209880406b483662a64.pdf, e também no documentário disponível em: https://www.youtube.com/ watch?v=KwIqpfiW0ko.

11 O Museu Histórico de Pinhalzinho está localizado no município de Pinhalzinho/SC e tem caráter municipal. Desenvolveu diversos projetos culturais de abrangência regional, alguns com a participação do município de Formosa do Sul. Maiores informações sobre o museu podem ser consultadas em: https://culturapzo.wordpress. com/museu-historico-de-pinhalzinho/.

12 Maiores informações sobre os referidos projetos, bem como amostras do material produzido, encontram-se disponíveis em: https://www.cataventoproducaocultural. com/portfolio.

\section{Referências}

ARGENTA, Denise Adriana. O ideal de museu e o museu real: uma análise dos museus do Oeste Catarinense. Orientador: Teresa Cristina Moletta Scheiner. 2011. Dissertação (Mestrado Profissionalizante em Patrimônio Cultural) - Programa de Pós-Graduação Patrimônio Cultural, Universidade Federal de Santa Maria, Santa Maria, 2011.

ASSOCIAÇÃO DOS MUNICÍPIOS DO OESTE DE SANTA CATARINA (AMOSC). Levantamento de dados. Plano Básico de Desenvolvimento Regional. Federação Catarinense de Municípios. [s. d.].

BEN, Fernanda; ARGENTA, Denise Adriana; RAFAEL, Maurício. Cartilha de apoio didático. Formosa do Sul: Museu Formosa do Sul, 2016.

\section{BRASIL. Lei $\mathrm{n}^{\mathrm{o}} \mathbf{1 1 . 9 0 4}$ de 14 de janeiro de}

2009. Institui o Estatuto de Museus e dá outras providências. Disponível em: http://www.planalto. gov.br/ccivil_03/_ato2007-2010/2009/lei/111904. htm. Acesso em: 18 abr. 2018. 
BURKE, Peter. Abertura: a nova história, seu passado e seu futuro. In: BURKE, Peter (Org.). A escrita da história: novas perspectivas. São Paulo: Editora da Universidade Estadual Paulista, 1992. p. 7-38.

CANDAU, Joel. Memória e identidade. São Paulo: Contexto, 2012.

CARBONERA, Mirian; ONGHERO, André Luiz; SALINI, Ademir Miguel; ROCHA, Douglas Saritio; ARGENTA, Denise Adriana. O trabalho com os bens culturais: a atuação do CEOM/Unochapecó no Oeste Catarinense. In: PAIM, Elison Antonio; GUIMARÃES, Maria de Fátima (Org.). Educar em tempos e espaços que se cruzam (ruas, escolas, museus e arquivos). Florianópolis: NUP, CED/ UFSC, 2017. p. 155-168.

CARBONERA, Mirian; ONGHERO, André Luiz; LINO, Jaisson Teixeira. Um passado distante, um patrimônio presente: o povoamento pré-colonial de Chapecó. In: CARBONERA, Mirian; ONGHERO, André Luiz; RENK, Arlene; SALINI, Ademir Miguel (Ed.). Chapecó 100 anos: histórias plurais. Chapecó: Argos, 2017. p. 19-58.

CASTRO, Hebe. História social. In: CARDOSO, Ciro Flamarion; VAINFAS, Ronaldo (Orgs.) Domínios da história: ensaios de teoria e metodologia. Rio de Janeiro: Campus, 1997, p. 76-96.

CHARTIER, Roger. A história ou a leitura do tempo. Belo Horizonte: Autêntica, 2007.

D’ANGELIS, Wilmar da Rocha. Para uma história dos índios do oeste catarinense. Cadernos do CEOM, n. 23, p. 265-343, 2006.

DMITRUK, Hilda Beatriz. Programa PEC: de qual história e de que patrimônio falar? Cadernos do CEOM, n. 12, p. 181-200, 2000.

EIDT, Paulino. Porto Novo: da escola paroquial ao processo de nucleação escolar - uma identidade em crise. Ijuí: Unijuí, 1999.

EIDT, Paulino. Os sinos se dobram por Alfredo. Chapecó: Argos, 2009.
FERNANDES, Ricardo Cid. Notícia sobre os processos de retomada de Terras Indígenas Kaingang em Santa Catarina. Campos, n. 4, p. 195$202,2003$.

FORMOSA DO SUL (Município). Lei Municipal n. 597, de 05 de novembro de 2013. Dispõe sobre a criação do Museu Histórico de Formosa do Sul. Disponível em https://leismunicipais.com.br/al/ sc/f/formosa-do-sul/lei-ordinaria/2013/59/597/leiordinaria-n-597-2013-dispoe-sobre-a-criacao-domuseu-historico-de-formosa-do-sul-e-da-outrasprovidencias. Acesso em: 15 out. 2019.

FORMOSA DO SUL (Município). Lei Municipal n. 621, de 15 de agosto de 2014. Altera a denominação do Museu Municipal criado pela Lei Municipal n. ${ }^{\circ}$ 597, de 05 de novembro de 2013. Disponível em https://leismunicipais.com.br/a/ sc/f/formosa-do-sul/lei-ordinaria/2014/63/621/ lei-ordinaria-n-621-2014-altera-a-denominacaodo-museu-municipal-criado-pela-lei-municipaln-597-de-05-de-novembro-de-2013?q=MUSEU. Acesso em: 15 out. 2019.

FORMOSA DO SUL (Município). Plano Museológico do Museu Formosa do Sul. Formosa do Sul: [s. n.], 2015.

FORMOSA DO SUL (Município). Plano Municipal de Cultura. Formosa do Sul: [s. n.], 2016.

FRIGO, Daiane. O museu como patrimônio da comunidade: reflexões sobre a implantação do Museu Formosa do Sul. In: SIMPÓSIO ESTADUAL DE HISTÓRIA - ANPUH, 7., 21-24 ago. 2018, Florianópolis. Anais [...]. Florianópolis: ANPUH, 2018. p. 1-15.

FRIGO, Daiane. O processo colonizatório e as relações interétnicas na Fazenda Saudades, oeste catarinense: memória, identidade e patrimônio. Orientadora: Mirian Carbonera. 2019. 137 f. Dissertação (Mestrado em História) - Programa de Pós-Graduação em História, Universidade Federal da Fronteira Sul, Chapecó, 2019.

FUNARI, Pedro Paulo; PELEGRINI, Sandra C. A. Patrimônio Histórico e Cultural. 2. ed. Rio de Janeiro: Zahar, 2009. 
INSTITUTO BRASILEIRO DE GEOGRAFIA E ESTATÍsTICA (IBGE). Formosa do Sul. 2018. Disponível em: https://cidades.ibge.gov.br/brasil/sc/ formosa-do-sul/panorama. Acesso em: 22 ago. 2018.

JUNGBLUT, Roque. Porto Novo: um documentário. Itapiranga: Edições FAI, 2000.

MICHELON, Francisca Ferreira; MACHADO JR., Cláudio de Sá; GONZÁLEZ, Ana María Sosa. Apresentação: políticas públicas do patrimônio. In: MICHELON, Francisca Ferreira; MACHADO JR., Cláudio de Sá; GONZÁlEZ, Ana María Sosa (Org.). Políticas públicas do patrimônio cultural: ensaios, trajetórias e contextos. Pelotas: Universidade Federal de Pelotas, 2012. p. 5-19.

MENESES, U. B. A história, cativa da memória? Para um mapeamento da memória no campo das ciências sociais. Revista Instituto de Estudos Brasileiros, n. 34, p. 9-24, 1992.

MUSEU FORMOSA DO SUL. 2019. Imagem Museu Formosa do Sul. Acervo Digital. 1 fotografia. Formato JPEG. Acesso em: 06 set. 2019.

NACKE, Anelise; RENK, Arlene; PIOVEZANA, Leonel; BLOEMER, Neusa Maria Sens. Os Kaingang no Oeste Catarinense: tradição e atualidade. Chapecó: Argos, 2007.

OLIVEIRA, Rafael Pereira. Políticas culturais e o campo museal em Santa Catarina (1987-2006). Orientadora: Rosimeri de Fátima Carvalho da Silva. 2007. 167 f. Dissertação (Mestrado em Administração) - Programa de Pós-Graduação em História, Universidade Federal de Santa Catarina, Florianópolis, 2007.

ONGHERO, André Luiz. Memórias e histórias do Oeste de Santa Catarina: a atuação do Programa Patrimônio-Escola-Comunidade CEOM/ Unochapecó. In: SIMPÓSIO NACIONAL DE HISTÓRIA - ANPUH, 27., 2011, São Paulo. Anais [...].São Paulo: ANPUH, 2011.

ONGHERO, André Luiz. Retratos e memórias da história de Formosa do Sul. Chapecó: CEOM/ Unochapecó, 2012.
PEIXE, João Roberto. A importância estratégica do Sistema Nacional de Cultura. In: MINISTÉRIO DA CULTURA (Ed.). Estruturação, institucionalização e implementação do Sistema Nacional de Cultura. Brasília: Ministério da Cultura/SESC-SP, 2011. p.14.

PIOVEZANA, Leonel. Território Kaingang na Mesorregião Grande Fronteira do Mercosul - Territorialidades em Confronto. Orientadora: Virgínia Elisabeta Etges. 2010. 286 f. Tese (Doutorado em Desenvolvimento Regional) Programa de Pós-Graduação em Desenvolvimento Regional, Universidade de Santa Cruz do Sul, Santa Cruz do Sul, 2010.

POLI, Odilon Luiz. Camponeses no Oeste Catarinense. Cadernos do CEOM, n. 4, p. 11-62, 2001.

POLI, Odilon Luiz. Cultura e modo de vida camponês no Oeste Catarinense: as bases para a organização e reação frente à crise dos anos 70 . Cadernos do CEOM, n. 15, p. 107-176, 2002.

RADIN, José Carlos. Representações da colonização. Chapecó: Argos, 2009.

RADIN, José Carlos; VICENZI, Renilda. A colonização em perspectiva no centenário de Chapecó. In: CARBONERA, Mirian; ONGHERO, André Luiz; RENK, Arlene; SALINI, Ademir Miguel (Ed.). Chapecó 100 anos: histórias plurais. Chapecó: Argos. 2017. p. 59-105.

RENK, Arlene. A luta da erva: um ofício étnico da nação brasileira no oeste catarinense. Chapecó: Argos, 1997.

RENK, Arlene. Migrações: de ontem e de hoje. Chapecó: Argos, 1999.

RENK, Arlene. Narrativas da Diferença. Chapecó: Argos, 2004.

RENK, Arlene; CONFORTIN, Priscila Fernanda Rech. Territorialidade e minorias sociais na construção da história local. In: CARBONERA, 
Mirian; ONGHERO, André Luiz; RENK, Arlene; SALINI, Ademir Miguel (Ed.). Chapecó 100 anos: histórias plurais. Chapecó: Argos. p. 137-158.

RODRIGUES, Donizete. Patrimônio Cultural, Memória Social e Identidade: uma abordagem antropológica. UBImuseumn, n. 1, p. 1-8, 2012.

SARTORI, Maria Ester de S. R. Entre tempo, memória e história se constroem as narrativas do passado. 10 abr. 2018. Disponível em: http:// www.itaucultural.org.br/entre-tempo-memoria-ehistoria-se-constroem-as-narrativas-do-passado. Acesso em: 22 ago. 2018.

SEYFERTH, Giralda. Colonização, imigração e a questão racial no Brasil. Revista USP, São Paulo, n. 53, p. 117-149, 2002.

SIMONI, Karine. Além da enxada, a utopia: a colonizaçãoitaliananooestecatarinense. Orientador: Valmir Francisco Muraro. 2017. 221 f. 2003. Dissertação (Mestrado em História) -Programa de Pós-Graduação em História, Universidade Federal de Santa Catarina, Florianópolis, SC, 2003.

SOUZA, Almir Antonio de. Armas, pólvora e chumbo: a expansão luso-brasileira e os indígenas doplanalto meridional na primeira metade do século XIX. Orientador: Paulo Pinheiro Machado. 2012. 428 f. Tese (Doutorado em História) - Programa de
Pós-Graduação em História, Universidade Federal de Santa Catarina, Florianópolis, 2012.

UNESCO. Manual de Referência do Patrimônio Mundial. Gestão do Patrimônio Mundial Cultural. Brasília: UNESCO Brasil; IPHAN, 2016.

VICENZI, Renilda. Mito e história na colonização do oeste catarinense. Chapecó: Argos, 2008.

VITÓRIA, Fernando Antônio. Uma nova história para o Velho Oeste: $\mathrm{O}$ "resgate" da memória e a reescrita da história do Oeste Catarinense no projeto do CEOM. [1986-2006]. Orientadora: Letícia Borges Nedel. 2017. 596 f. Tese (Doutorado em História) - Programa de Pós-Graduação em História, Universidade Federal de Santa Catarina, Florianópolis, 2017.

WERLANG, Alceu Antônio. Disputas e ocupação do espaço no oeste catarinense: a atuação da Companhia Territorial Sul Brasil. Chapecó: Argos, 2006.

WERLE, André Carlos. O Reino JesuíticoGermânico nas margens do Rio Uruguai. Aspectos da formação da Colônia Porto Novo (Itapiranga). Orientador: Valberto Dirksen. 2001. 204 f. Dissertação (Mestrado em História) - Programa de Pós-Graduação em História, Universidade Federal de Santa Catarina, Florianópolis, 2001. 